\title{
Algılanan Çalışan Performansı ile İşletme Performansı Arasındaki ilişkide Yenilikçi İş Davranışının Düzenleyicilik Etkisi
}

\author{
Berat Çiçek $^{1}$ \\ Metin Işı $\left.\right|^{2}$
}

\begin{abstract}
Algılanan Çalışan Performansı ile İşletme Performansı Arasındaki ílişkide Yenilikçi İş Davranışının Düzenleyicilik Etkisi
\end{abstract}

Öz

İşletmelerin kendilerini ve çalışanlarını değerlendirebilmesinin yolu performans değerlendirme faaliyetleridir. Ayrıca günümüz işletmecilik mantığının en önemli unsurlarından bir tanesi yeniliktir. Fakat yenilik zaman zaman işletmelerin uzak durduğu ve denemekten korktuğu bir olgu haline gelmektedir. Hatta yenilikçi davranışların olumlu bir çıktı sağlaması gerekirken olumsuz sonuçlar doğurabildiğine şahit olunabilmektedir. Bu bağlamda araştırmada lojistik işletmelerindeki algılanan çalışan performansı ile işletme performansı arasındaki ilişkinin ve bu ilişkide yenilikçi iş davranışının etkisinin ortaya konulması amaçlanmıştır. Bu amaç doğrultusunda TRB-2 bölgesinde nicel bir araştırma gerçekleştirilmiştir. Anket yöntemiyle elde edilen verilerin bulgularına göre; algılanan çalışan performansının işletme performansını pozitif yönde etkilediği ve yenilikçi iş davranışının bu ikisi arasındaki ilişkide negatif yönlü bir düzenleyicilik etkisine sahip olduğu sonucuna ulaşılmıştır.

Anahtar Kelimeler: Algılanan Çalışan Performansı, İşletme Performansı, Yenilikçi İ̧̧ Davranışı, Lojistik Sektörü, TRB-2 Bölgesi
Moderator Effect of Innovative Work Behavior on the Relationship Between Perceived Employee Performance and Firm Performance

Abstract

The way for enterprises to evaluate themselves and their employees is performance evaluation activities. In addition, innovation is one of the most important elements of today's business logic. However, innovation has become a phenomenon from which enterprises sometimes avoid or which they are afraid to try from time to time. In fact, while innovative behaviors are supposed to provide a positive output, negative consequences can be observed. In this context, it is aimed to determine the relationship between perceived employee performance and firm performance in logistics enterprises and the effect of innovative work behavior on this relationship. For this purpose, a quantitative study was carried out in the TRB2 region. According to the findings obtained by the survey method; it was concluded that perceived employee performance positively affects the firm performance and innovative work behavior has a negative moderator effect on the relationship between these two performances.

Keywords: Perceived Employee Performance, Firm Performance, Innovative Work Behaviour, Logistics Sector, TRB-2 Region

\section{Giriş}

Illk defa Schumpeter (1934) tarafından kullanılan yenilik kavramı, müşterilerin bilmediği bir ürünün ya da müşterilerin bilmediği bir ürün özelliğinin; yeni bir pazara sürülmesi, daha önce girilmemiş bir pazara açılması, tedarik konusunda yeni bir kaynağın bulunması, yeni bir üretim yönteminin uygulanmaya başlanması ve bir sanayinin yeni bir organizasyon yapısına sahip olması olarak tanımlanmıştır. Ayrıca kalkınmanın itici gücü olarak nitelendirilmiştir. Böylece yeniliğin ekonomik gelişme iç̧in olmazsa olmaz olduğunu savunmuştur. Kavramı işletmeler açısından ele alan Drucker (1998) ise uzun vadeli firma performansını yenilik ile ilişkilendirerek yeniliğin; değişen çevre koşullarına uyum, verimlilik ve esneklik gibi konulara önemli katkı sunabileceğini ve küresel rekabet ortamında uzun vadede örgütsel başarıyı arttıran bir unsur olduğunu iddia etmiştir.

\footnotetext{
${ }^{1}$ Dr. Öğr. Üyesi, Muş Alparslan Üniversitesi, iiBF, İşletme Bölümü. b.cicek@alparslan.edu.tr, Yazar ORCID bilgisi: http://orcid.org/0000-0002-4584-5862

2 Dr. Öğr. Üyesi, Bitlis Eren Üniversitesi, iỉB, İşletme Bölümü. imetin@beu.edu.tr, Yazar ORCID bilgisi: http://orcid.org/0000-0003-4577-0095
} 
Yenilikçilik olgusu, işletmelerin verimlik ve etkinliklerini artırmaları ve rekabet edebilmeleri için son derece önemlidir (Osterloh ve Frey, 2000). Genel itibariyle, işletmeler herhangi bir olumsuz durumla karşı karşıya geldiğinde ya da işletme performansının beklenen seviyede olmadığı durumlarda bunun üstesinden gelebilmek için yenilik yapma ihtiyacı hissetmekte ve yenilikçi iş davranışını geliştirmeye eğilim göstermektedir (De Jong ve Den Hartog, 2010: 24). Çünkü yenilikçi iş davranışı bireysel ve/veya işletme performansını arttırmak için yeni bilgilerin uygulanması veya süreçlerin iyileştirilmesi ve geliştirilmesi için uygulanan davranışları kapsamaktadır (Işık, 2018: 646). Yenilikçi iş davranışı, De Jong (2006: 19) tarafından; bireylerin davranışlarının yeni veya yararlı fikirlerin, süreçlerin, ürünlerin veya prosedürlerin iş rolü, grup ya da örgüt içinde başlatılması ve yönlendirilmesi olarak tanımlanmıştır. Janssen (2005) yenilikçi iş davranışının, işletme performansı geliştirmeyi amaçlayan iş rolü, grup veya organizasyonda amaçlanan yeni fikirlerin üretimi, tanıtımı ve uygulanmasından oluşan karmaşık bir çalışma davranışı olduğunu belirtmiştir. Çalışanların potansiyellerini açığa çıkarmak ve harekete geçirmek çok kolay olmadığından yenilikçi iş davranışı bu bakımdan karmaşık bir özellik taşımaktadır. Çünkü insan doğası gereği yeni veya farklı olan bir şeye genellikle temkinli yaklaşmakta ya da bundan kaçınmayı tercih etmektedir. Ancak bir işletme politikası olarak yenilikçilik olgusu benimsendiği takdirde, süreç içerisinde çalışanların yenilikçi iş davranışları sergilemelerini özendirmek mümkündür. Bu davranışı sergileyen çalışanların bireysel performanslarında iyileşme olacağı gibi işletmenin genel performansını da artıracağını söylemek mümkün.

Literatürde, işletmelerin kendilerini ve çalışanlarını değerlendirmelerinin gerekliliği sıklıkla ele alınmakta olan bir konudur. Bu çalışmaların genellikle kesiştiği nokta, çalışan performansının yükselmesinin işletme performansı üzerinde de olumlu etkilere sahip olacağı yönündedir (Gosselin, 2005; Schuster ve Zingheim, 1996; Wexley, 1994). Performansı etkileyen unsurlar birçok çalışmanın konusunu oluşturmuştur. Bu bağlamda çeşitli değişkenlerin performansı nasıl etkilediği araştırılmıştır.

Bu çalışmada algılanan çalışan performansı ile işletme performansı arasındaki ilişkide yenilikçi iş davranışının etkisi ortaya konulmaya çalışımıştır. Yenilik doğası gereği insanların alışkanlıklarını bozduğundan güvenlik duygularını tehdit edebilmektedir. Bu nedenle kolayca kabul edilemeyen bir olgudur. Hal böyle olunca ortaya "yeniliğin performansa olan etkisi" gibi bir sorunsal çıkmaktadır. Bu sorunsaldan hareketle yeniliğe açık bir sektör olduğu düşünülen lojistik işletmelerindeki çalışan ve yöneticilerin yenilikçi iş davranışlarına karşı tutumlarının performanslarını nasıl etkilediğinin ortaya konulması amaçlanmıştır. Sektörün yeniliğe açıklığı göz önünde bulundurulduğunda, algılanan çalışan performansının işletme performansını pozitif yönlü etkilemesi ve bu iki değişken arasındaki ilişkide yenilikçi iş davranışının düzenleyicilik rolüne sahip olması beklenilmektedir.

\section{Kavramsal Çerçeve}

\subsection{Yenilikçi îş Davranışı}

Yenilik kavramı, "yeni bir şeyler yapmak" anlamına gelen Latince "innovare" kelimesinden gelmektedir (Tidd vd., 2005: 16) ve literatürde çoğunlukla ortaya sürülen yeni fikirlerin ürün, süreç, hizmet ve iş uygulamalarına dönüştürülmesi; bunların başarı ile kullanılması olarak tanımlanmaktadır (Banbury ve Mitchell, 1995: 163). Yeniliğin bir gereklilik olduğunu savunana Drucker (1998) işletmelerin amaçlarının yalnızca müşterilerine hizmet vermek değil aynı zamanda yaşam kalitelerini yükseltmek ve değişiklikleri teşvik etmek olduğunu belirtmiştir. 
Yenilikçi iş davranışı ise en genel anlamda organizasyonun herhangi bir düzeyinde yararlı bir yeniliğin geliştirilmesi, tanıtılması ve uygulanması yönündeki tüm faaliyetler olarak tanımlanmaktadır (West ve Farr, 1989). Yenilik yapmak basit gibi görünse de aslında hiç kolay olmayan, piyasaya karşı büyük bir meydan okumadır. Başarılı bir yenilik girişiminin ardından pazar liderliğini ve rekabetçi ivmeyi sağlayan da aslında bu meydan okumadır (Pearson, 2003: 58). Bütün bu yenilikçi davranışları gösterebilmenin yolu ise iyi yetişmiş ve kalifiye insan kaynaklarından geçmektedir. Çünkü bütün yenilikler yaratıcı fikirler ile başlar. Yeni programların, yeni ürünlerin, yeni servislerin başarılı bir şekilde gerçekleştirilmesi ancak iyi bir fikre sahip birey veya ekiplere bağlıdır. Başka bir deyişle bireylerin veya ekiplerin yaratıcı olması, yeniliğin başlangıç noktasını oluşturmaktadır (Amabile, 1988; Kheng vd., 2013; Scott ve Bruce, 1994).

Çalışanların yenilikçilik davranışı, çeşitli bakış açıları ile tanımlanmıştır. Bir kısım araştırmacılar (Amabile, 1988; Kuratko vd., 2011; Scott ve Bruce, 1994) yenilikçi davranışı, bireylerin kişisel özellikleri ile tanımlarken; diğer bir kısım araştırmacılar (Bushra vd., 2011; De Jong ve Den Hartog, 2007; Yidong ve Xinxin, 2013) ise davranışsal perspektif ve çevrenin etkisiyle tanımlamışlardır. Kanter (2009), bir organizasyonda yenilikçilik sürecini bir çiçeğin tohumdan, çiçek açıp sonra kokusunun yayılması süreçlerine benzetmiştir. Yenilikler, çiçekler gibi küçük tohumlar ile başlar ve çiçekler açana kadar dikkatli bir şekilde yetiştirmek gerekir. Toprak, iklim, gübre, bahçe düzeni daha büyük ve daha bol çiçek için nasıl etkili ise yeniliklerin meydana geldiği ortam ve bağlamsal faktörler de o kadar önemlidir. Kanter'inde (2009) tanımlamasından anlaşılacağı üzere yenilikçi iş davranışını tek bir faktöre indirgemek ve tek bir değişken üzerinden açıklamak pek mümkün değildir. Yenilikçi iş davranışının oluşumunda birey, organizasyon ve yenilikçilik iklimi büyük önem taşımaktadır.

Toffler'a (2006: 31) göre yenilik birbirini üç evrede tamamlamaktadır.

1. Yaratıcı, uygulanabilir düşüncenin varlığı,

2. Bu yaratıcı ve uygulanabilir düşüncenin pratikte uygulanması,

3. Uygulanan düşüncenin topluma yayılmasından oluşmaktadır.

Yenilik literatüründe sıkça kullanılan yaratıcılık, yeniliğin oluşturulabilmesi için oldukça önemlidir. Fakat her ne kadar yaratıcılık ve yenilik birbiriyle ilişkili olsa da eş anlamlı değildir (Çalışkan, 2013: 95). Aralarındaki ilişkide en önemli fark, yaratıcılığın kendiliğinden yeniliği getiremeyeceğidir. Başka bir deyişle bir fikir oluşturmak ile bir yenilik yapmak eş anlamlı kabul edilemez. Fikir oluşturmak sürecin düşünsel boyutu iken, yenilik eylemsel boyutu ifade etmektedir (Levitt, 2003: 165). Bu bağlamda Amabile (1988) spesifik faktörleri tanımlama yerine genel olarak bireyin içinde bulunduğu bağlamsal çevrenin yaratıcılık üzerinde etkili olduğunu gösteren bir model oluşturmuştur. Bu modelde yalnızca bireysel bazda değil de grup bazında ve örgütsel bazda yaratıcılığı etkileyen faktörleri de kategorize etmişlerdir. Amabile (1988) tarafından oluşturulan model Şekil 1'de verilmiştir. 
Şekil 1: Yaratıcılık ve Yenilik ilişkisi

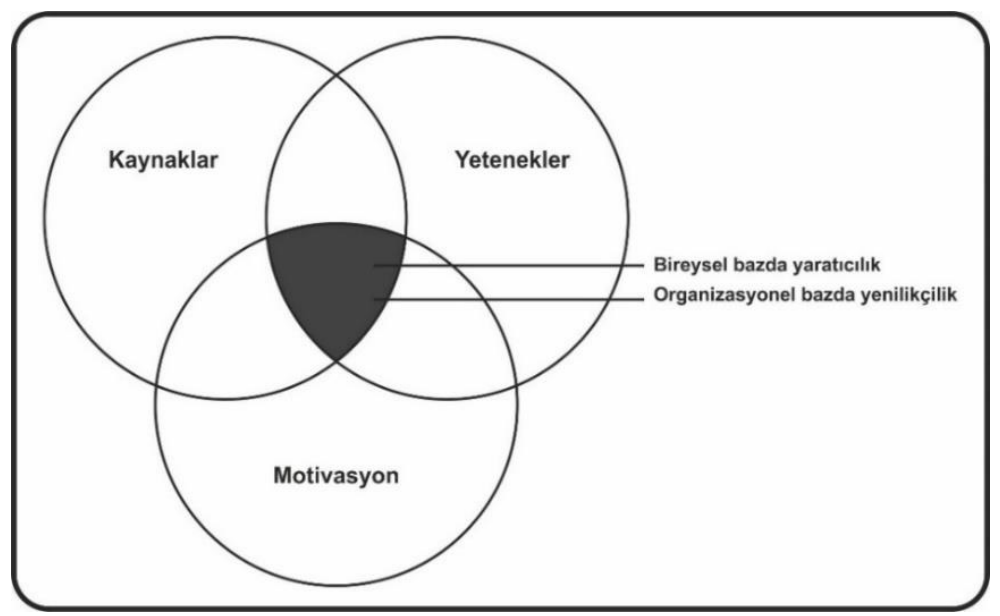

\section{2. Çalışan ve iş̧letme Performansı}

En genel anlamıyla çalışan performansı; çalışanın görevleri çerçevesinde önceden belirlenen hedefleri karşılayacak şekilde, görevin yerine getirilmesi ve amacın gerçekleştirilmesiyle ortaya konan mal, hizmet ya da fikirdir (Brayfield ve Crockett, 1955; Noe vd., 2006; Salanova vd., 2005). Üretim yapan işletmelerde iş performansı, başarının değerlendirilmesi için bir anahtar olarak görüldüğünden, çalışan performansı kimi kaynaklarda iş performansı olarak da geçebilmektedir. Fakat hizmet sektöründe faaliyette bulunan işletmelerin çalışanlarının performansını görülen iş üzerinden ölçmek pek kolay olmayan bir durumdur (Sureshchandar vd., 2002), bu nedenle kavram zaman içerisinde çalışan performansı tanımlamasına sahip olmuştur.

Çalışan performansı kavramına daha spesifik olarak bakacak olursak kavram karşımıza, kişinin kontrolü altında ve yeteneği doğrultusunda ayarlanabilen herhangi bir davranış veya etkinlik olarak çıkmaktadır (Lado ve Alonso, 2017: 176). Maddiyat vurgusu yapan araştırmacılar ise çalışan performansı için, işgörenlerin çabalarının mali ve mali olmayan sonuçlarını gösterdiğini belirtmişlerdir (Anitha, 2014: 313). Kavram somutlaştırma üzerinden ele alınacak olursa "işletme stratejisinin somut çıktılara dönüşmesi" olarak tanımlanabilir (Gates, 1999: 1). Her ne kadar çalışan bir performans sergilese de sonuçta sergilenen bu performans örgütlerin karlılığında etkili olduğu, örgütler için etkinlik ve verimlilik sağladığı, kalitenin belirlenmesine yardımcı olduğu, müşteri açısından önem taşıdığı için örgütün bütününün başarısı olarak görülmektedir (Gosselin, 2005: 420).

İşletme performansı, bir kuruluşun önceden belirlenen amaçlara ve hedeflere göre ortaya çıkan ürünleri, hizmetleri ve/veya sonuçları birlikte değerlendirmesine yönelik analitik bir süreç olarak tanımlanmaktadır (Bayrakdaroğlu ve Ege, 2007). İşletmeleri performans ölçmeye iten başlıca nedenler ise; geçmişte nerede olduklarını, şu an nerede olduklarını, nereye gitmek istediklerini, oraya nasıl gideceklerini ve oraya ulaştıklarını nasıl anlayacaklarını bilmek istemeleridir (Lebas, 1995: 24). İşletme performansını ölçerken kullanılan göstergeler ise yatırımların geri dönüşü, satışlardaki artış, müşteriyi elde tutma düzeyi, kâr oranı, büyüme hızı, pazar payındaki artış, işletme büyüklüğü ve genel başarı gibi faktörlerdir (Kılıçer, 2011: 80). Başka bir deyişle performans ölçümü, faaliyetlerin etkililiğini ve etkinliğini sayısallaştırma sürecidir ( $\mathrm{Ne}$ ely vd., 1995). 
İşletme performansının bahsedilen somut sayısal veriler ile ölçülmesi objektif ölçütler olarak ifade edilmektedir. Dess ve Robinson (1984: 265-266) işletmelerin nicel verilerine ulaşmanın çoğu kez güç olduğunu veya işletmelerin söz konusu verileri paylaşma noktasında pek istekli olmadıklarını ifade etmiştir. Bu nedenle objektif ölçütlerin ikamesi olarak kabul edilen sübjektif ölçütlerle de (çalışan veya müşteri algısı gibi) işletme performansının ölçülebileceğini belirtmişlerdir. Bu çalışmada da işletme performansı, çalışanların algılarıyla ölçülmesi yoluna gidilmiştir.

\section{Araştırmanın Yöntemi}

Algılanan çalışan performansının (AÇP) işletme performansı (IP) üzerindeki etkisinde yenilikçi iş davranışının (YiD) düzenleyici etkisini ortaya konulması amaçlanan bu araştırmada, ilk olarak örneklem ve ölçeklere ilişkin bilgilere, daha sonra elde edilen veriler doğrultusunda oluşturulan modele ilişkin yapılan analizlere yer verilmiştir. Bu bağlamda, öncelikle her bir değişkenin doğrulayıcı faktör analizi yapılmış, ardından değişkenler arası korelasyonlar tespit edilmiştir. Bağımsız değişkenin (algılanan çalışan performansı) bağımlı değişken (işletme performansı) üzerindeki etkisinde düzenleyici (moderator) değişkenin (yenilikçi iş davranışı) düzenleyicilik etkisini tespit etmek amacıyla hiyerarşik regresyon analizleri yapılmıştır. Çalışmada literatür taraması sonucunda oluşturulan hipotezler ve geliştirilen araştırma modeli Şekil 2' de sunulmuştur.

Şekil 2: Araştırma Modeli

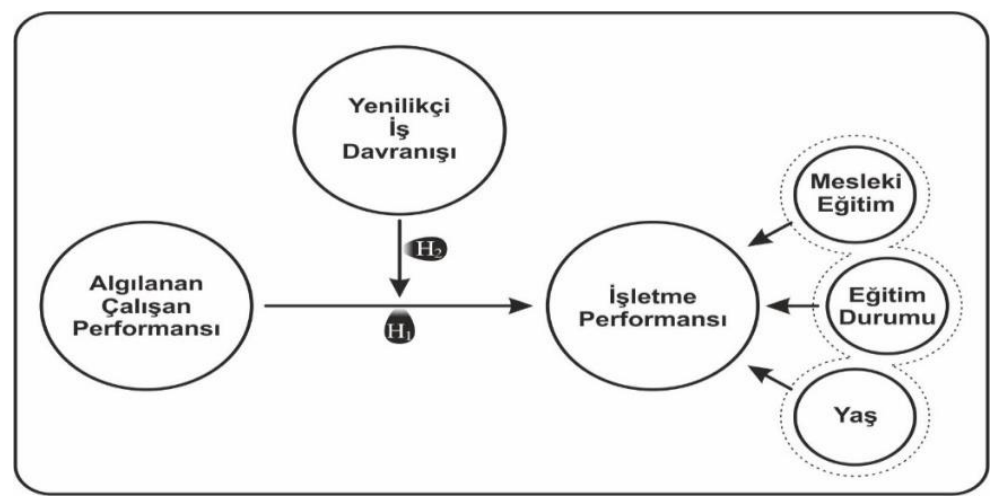

$\boldsymbol{H}_{1}$ :Algılanan çalışan performansı işletme performansını olumlu yönde etkiler.

$\boldsymbol{H}_{2}$ :Algılanan çalışan performansının işletme performansına etkisinde yenilikçi iş davranışının düzenleyici rolü vardır.

\subsection{Katılımcilar}

Araştırmanın ana kütlesini TRB-2 bölgesinde faaliyet gösteren lojistik firmaları oluşturmaktadır. Firmalar belirlenirken ulaşılabilirlik ve veri toplama kolaylığı göz önünde bulundurulmuştur. Bölgede yaklaşık olarak (evden eve nakliyat firmaları hariç) 37 firma olduğu tespit edilmiştir. Bu firmalardan 6 tanesine bazı nedenlerden dolayı ulaşılamadı̆̆ından araştırmaya dahil edilmemiştir. Firmalardan 29 tanesinin ilgili birimleri veya firma sahipleri ile yapılan görüşmelerde yaklaşık 426 çalışan olduğu belirtilmiştir. Bu doğrultuda örneklem oluşturmak amacıyla kolayda örnekleme yöntemi benimsenmiştir. Araştırmanın örneklemi bu firmalarda çalışan ve gönüllü olarak anket formunu doldurmayı kabul eden 308 kişiden oluşmaktadır. Veri toplama sürecinde çalışanların cevaplamaları için hazırlanan anket formunun bir kısmı elden teslim edilmiş, bir kısmı ise elektronik ortamda yanıtlanması için katılımcıların Whatsapp uygulama- 
sındaki çalışma gruplarına gönderilmiştir. Katılımcıların cinsiyet, yaş, medeni durum, eğitim durumu ve mevcut işyerlerindeki çalışma sürelerine ilişkin demografik bilgiler Tablo 1'de belirtilmiştir.

Tablo: 1 Katılımcıların Demografik Bilgileri

\begin{tabular}{|c|c|c|c|c|c|c|c|}
\hline \multicolumn{2}{|c|}{ Değişkenler } & \multirow[b]{2}{*}{98} & \multirow{2}{*}{$\begin{array}{r}\text { \% } \\
31,82 \\
\end{array}$} & \multicolumn{2}{|c|}{ Değişkenler } & \multirow[b]{2}{*}{37} & \multirow{2}{*}{$\begin{array}{r}\% \\
12,01 \\
\end{array}$} \\
\hline \multirow{3}{*}{ Cinsiyet } & Kadın & & & \multirow{6}{*}{ Yaş } & 25 ve Altı & & \\
\hline & Erkek & 210 & 68,18 & & $26-31$ & 124 & 40,26 \\
\hline & Toplam & 308 & 100,0 & & $32-37$ & 98 & 31,82 \\
\hline \multirow{3}{*}{$\begin{array}{l}\text { Medeni } \\
\text { Durum }\end{array}$} & Evli & 221 & 71,75 & & $38-43$ & 22 & 7,14 \\
\hline & Bekar & 87 & 28,25 & & 44 ve üzeri & 27 & 8,77 \\
\hline & Toplam & 308 & 100,0 & & Toplam & 308 & 100,0 \\
\hline \multirow{5}{*}{$\begin{array}{c}\text { Eğitim } \\
\text { Durumu }\end{array}$} & Lise & 186 & 60,38 & \multirow{5}{*}{$\begin{array}{l}\text { Çalışma } \\
\text { Süresi }\end{array}$} & 1-4 yıl & 75 & 24,3 \\
\hline & Önlisans & 68 & 22,08 & & 5-9 yıl & 130 & 42,2 \\
\hline & Lisans & 36 & 11,69 & & $10-14$ yıl & 56 & 18,2 \\
\hline & Lisansüstü & 18 & 5,84 & & 15 yıl ve üzeri & 47 & 15,3 \\
\hline & Toplam & 308 & 100,0 & & Toplam & 308 & 100,0 \\
\hline
\end{tabular}

\section{2. Ölçüm Araçları}

Algılanan Çalışan Performansı: Algılanan çalışan performansının ölçülmesinde Bush vd., (1990) tarafından geliştirilen, Erkuş ve Fındıkıının (2013) araştırmalarında kullanmış oldukları bireylerin algıladıkları iş performanslarının belirlenmesine yönelik 3 ifadeli ölçek kullanılmıştır. Ölçekte yer alan ifadeler: "Görevlerimi kısa sürede tamamlarım”, "Zamanımı birçok çalışandan daha iyi yönetirim", "iş performansım diğer çalışanlardan daha iyidir" şeklindedir.

İşletme Performansı: İşletme performansı Zerenler'in (2005) araştırmasında kullanmış olduğu ölçek yardımıyla ölçülmüştür. Söz konusu ölçek yedi ifadeden oluşmaktadır. İşletme performansının ölçülmesinde genel kârlılık, satışlardaki büyüme ve pazar payı gibi objektif ölçütlerden yararlanılanabileceği gibi; müşteri ve çalışan memnuniyetine dayanan sübjektif ölçütlerle de ölçülebilmektedir (Erdil ve Kitapçı, 2007: 237). Naktiyok ve Küçük (2003: 53) ile Erdem vd., (2011: 92) objektif ölçütlerin işletme performansının tespit edilmesindeki en uygun yöntem olduğunu ancak, işletmelerin gerçek performans verilerini bulmanın pek mümkün olmadığından araştırmacılar, işletme performansının ölçülmesinde sübjektif değerlendirmelerin güvenilir bir yöntem olduğunu ifade etmektedirler. Yine, araştırmacılar, işletme performansının algılanan ölçümünün, objektif performans ölçümünün uygun bir ikamesi olduğunu belirtmişlerdir.

Yenilikçi iş Davranışı Ölçeği: Yenilikçi iş davranışı ölçmek için Scott ve Bruce (1994) tarafından geliştirilen Akkoç vd., (2011) tarafından Türkçeye uyarlanmış 6 ifadeli versiyonu kullanılmıştır.

Kontrol Değişkenleri: Şekil 2'deki modelden de görüleceği üzere "Mesleki Eğitim, Eğitim Durumu ve Yaş" değişkenleri bağımlı değişkeni etkileyebileceği düşüncesiyle kontrol değişken olarak modele dahil edilmiştir.

Ölçekler için Likert tipi 7'li ölçeklendirme kullanılmıştır ve 1= "kesinlikle katılmıyorum", 7= "kesinlikle katılıyorum" olarak kodlanmıştır.

\subsection{Verilerin Analizi}

Araştırma kapsamında elde edilen veriler SPSS 25.0 paket programı ile PROCESS Makro 3.2 (Hayes, 2012) kullanılarak analiz edilmiştir. Araştırmada öncelikle katılımcıların demografik özellikleri ve araştırma değişkenlerine yönelik tanımlayıcı istatistiki analizler gerçekleştirilmiş- 
tir. Ölçeklerin geçerliliğini test etmek için yakınsak geçerlilik yöntemi izlenmiştir. Buna göre öncelikle tüm faktör yükleri anlamlı ve 0.50 değerinin üzerinde olmalıdır, ilgili yapılara göre maddelerdeki ortalama varyans (AVE) açıklanamayan varyanstan daha büyük olmalıdır ve faktör kompozit (CR) güvenilirliği 0,60 veya daha büyük olmalıdır (Fornell ve Larcker, 1981; Hu ve Bentler, 1999). Araştırmada kullanılan ölçeklerin bu değerleri sağladığı görülmüştür. İlgili değerler Tablo 3'te verilmiştir. Analiz kapsamında modelde çoklu doğrusal bağlantı sorunu olup olmadığını belirlemek maksadıyla doğrudaşlığa (collinearity) bakılmıştır. Elde edilen VIF değerleri $(\operatorname{VIF}(A C ̧ P)=1,751 ; \operatorname{VIF}(\mathrm{YID})=1,932 ; \operatorname{VIF}(\mathrm{IP})=1,624)$ bağımsız değişkenler arası çoklu bağlantı olmadığını doğrulayan (VIF<5) sonuçlar vermiştir (Craney ve Surles, 2002).

Araştırmada yer alan hipotezlerin sınanması için ise korelasyon ve hiyerarşik regresyon analizleri yapılmıştır. Hiyerarşik regresyon analizinin ilk aşamasında, kontrol değişkenleri (yaş, eğitim durumu ve mesleki eğitim) ve algılanan çalışan performansı (bağımsız değişken), ikinci aşamasında yenilikçi iş davranışı ve üçüncü aşamasında ise AÇP x YiD (algılanan çalışan performansı x yenilikçi iş davranışı: etkileşim değişkeni) modele dahil edilerek, kontrol, bağımsız ve düzenleyici değişkenlerin bağımlı değişken üzerindeki etkileri incelenmiştir.

\subsection{Bulgular}

Aşağıda Tablo 2'de araştırmada kullanılan ölçeklere yönelik yapılan doğrulayıcı faktör analizi (DFA) ile güvenilirlik analizi sonucunda elde edilen bulgular belirtilmiştir. Algılanan çalışan performansı ölçeğinin tek boyutu bir yapı oluşturduğu ve faktör yüklerinin $(, 755)$ ile $(, 915)$ arasında değerler aldığı tespit edilmiştir. İşletme performansı ölçeğine yönelik yapılan DFA'nde bir tane faktörün değerinin düşük olduğu $(, 389)$ görülmüş ve analizden çıkarılarak yeniden yapılan analizde ölçeğin tek boyutlu (6 ifade) ve faktör yüklerinin $(, 799)$ ile $(, 967)$ arasında olduğu görülmüştür. Yenilikçi iş davranışı ölçeğinin de tek boyutlu ve faktörlerin $(, 813)$ ile $(, 910)$ arasında yüklendiği tespit edilmiştir. Tablo 2'den de görüleceği üzere değişkenlere ait Cronbach Alpha değerlerinin ölçeklerin güvenilir olduğunu göstermektedir.

Tablo: 2 Ölçeklerin Kaiser Meyer Olkin (KMO) ve Cronbach Alpha Değerleri

\begin{tabular}{llccc}
\hline \multicolumn{1}{c}{ Ölçekler } & KMO & Bartlett & $\begin{array}{c}\text { Toplam Açılanan } \\
\text { Varyans }\end{array}$ & Cronbach Alpha \\
\hline Algılanan Çalışan Performansı &, 914 & 899,700 & 73,30 & 0,965 \\
İşletme Performansı &, 936 & 1214,290 & 80,87 & 0,961 \\
Yenilikçi İş Davranışı &, 937 & 1566,855 & 73,83 & 0,940 \\
\hline
\end{tabular}

Tablo 3'te belirtilen korelasyon analizinden de görüleceği üzere bütün değişkenler arasında istatistiki açıdan pozitif yönlü yüksek düzeyde ilişkiler olduğu tespit edilmiştir. Algılanan çalışan performansı ile işletme performansı $(r=, 576 ; p<0.01)$ ve yenilikçi iş davranışı $(r=, 632$; $p<0.01$ ) arasında yüksek düzeyde pozitif yönlü ve işletme performansı ile yenilikçi iş davranışı $(r=, 620 ; p<0.01)$ arasında yine yüksek düzeyde pozitif yönlü ilişki olduğu görülmektedir.

Tablo: 3 Tanımlayıcı Istatistikler ve Korelasyon Analizi

\begin{tabular}{lllllllll}
\hline \multicolumn{1}{c}{ Değişkenler } & CR & AVE & MSV & Ort. & Ss. & $\mathbf{1}$ & $\mathbf{2}$ & $\mathbf{3}$ \\
\hline (1) AÇP &, 962 &, 739 &, 422 & 3,99 &, 96 & - & - & - \\
(2) iP &, 942 &, 655 &, 399 & 5,34 &, 74 &, $576^{* *}$ & - & - \\
(3) YiD &, 943 &, 733 &, 422 & 4,21 & 1,11 &, $632^{* *}$ &, $620^{* *}$ & -
\end{tabular}

$\mathrm{N}=308 ;{ }^{* *}$ < $<0.01 ; \mathrm{AÇP}=$ Algılanan Çalışan Performansı; iP= İşletme Performansı; Yid = Yenilikçi İş Davranışı; CR= Composite Reliability; AVE= Average Variance Extracted; MSV= Maximum Shared Variance; Ort= Ortalama Değer; Ss= Standart Sapma. 
Tablo 4'te bağımsız değişkenin bağımlı değişken üzerindeki etkisi ve açıklama gücü ile bu etkide diğer bağımsız değişkenin düzenleyici rolünü ortaya koymak amacıyla hiyerarşik regresyon analizleri yapılmıştır. Analizlerde, ilk olarak; yaş, eğitim durumu, mesleki eğitim kontrol değişkeni ve algılanan çalışan performansı bağımsız değişken, işletme performansı bağımlı değişken olarak analiz edilmiştir. İkinci aşamada yenilikçi iş davranışı modele dahil edilmiştir. Üçüncü aşamada ise etkileşim (AÇP x YiD) değişkeni modele dahil edilerek bağımlı değişken üzerindeki etkileri incelenmiştir.

Tablo: 4 Algılanan Çalışan Performansının Iş̧letme Performansına Etkisinde Yenilikçi işs Davranışının Düzenleyici Etkisine Yönelik Hiyerarşik Regresyon Analizi

\begin{tabular}{|c|c|c|c|c|c|}
\hline & Değişken & $\beta$ & $\mathbf{R}^{2}$ & Düz. $R^{2}$ & $\mathbf{F}$ \\
\hline \multirow[t]{5}{*}{ 1.Aşama } & Yaş & ,030 & ,365 & ,350 & 23,589 \\
\hline & Eğitim Durumu & 123 & & & \\
\hline & Mesleki Eğitim &,$- 138 *$ & & & \\
\hline & AÇP &, $562 * * *$ & & & \\
\hline & Değişken & $\beta$ & $\mathbf{R}^{2}$ & Düz. $\mathbf{R}^{2}$ & $\mathbf{F}$ \\
\hline \multirow[t]{6}{*}{ 2.Aşama } & Yaş & ,028 & 475 & ,459 & 29,519 \\
\hline & Eğitim Durumu & 111 & & & \\
\hline & Mesleki Eğitim &,$-152^{* *}$ & & & \\
\hline & AÇP &, $292 * * *$ & & & \\
\hline & YID &, $429 * * *$ & & & \\
\hline & Değişken & $\beta$ & $\mathrm{R}^{2}$ & Düz. $\mathbf{R}^{2}$ & $\mathbf{F}$ \\
\hline \multirow[t]{6}{*}{ 3.Aşama } & Yaş & ,002 & ,572 & ,556 & 36,019 \\
\hline & Eğitim Durumu & 114 & & & \\
\hline & Mesleki Eğitim &,$- 124 *$ & & & \\
\hline & AÇP & ,203* & & & \\
\hline & YID &, $266^{* *}$ & & & \\
\hline & AÇP $\times$ YID &,$- 389 * * *$ & & & \\
\hline \multicolumn{6}{|c|}{$\mathrm{N}=308 ; * * *_{\mathrm{p}}<0,001 ; * * \mathrm{p}<0,01 ; *^{*}<<0,05$} \\
\hline
\end{tabular}

Tablo 4'te sunulan analiz sonuçlarına göre (birinci aşamada) AÇP ile IP ilişkinin pozitif ve anlamlı olduğu ( $\beta=.562, p<.001$ ) görülmüştür. Algılanan çalışan performansının işletme performansı üzerindeki varyansın \%37'sini açıkladığı görülmüştür. Bu durumda $\boldsymbol{H}_{\boldsymbol{1}}{ }^{\prime}$ in desteklendiği görülmektedir. Bu sonuç çalışanların performanslarına yönelik algılarının işletme performansını arttıran bir faktör olduğunu göstermektedir. Yine bu analiz sonucunda yenilikçi iş davranışının da işletme performansına olumlu yönde etki ettiği ve işletme performansını arttıran bir faktör olduğu tespit edilmiştir $(\beta=.429, p<.001)$. İkinci aşamada, AÇP ve YiD birlikte modele eklenmiş ve her iki değişkeninde iP ile istatistiksel olarak anlamlı ve pozitif yönlü ilişkilere sahip olduğu görülmüştür. Üçüncü aşamada ise, AÇP, YiD ve etkileşim değişkeni (AÇP $x$ YiD) birlikte modele eklenmiş ve iP ile istatistiksel olarak anlamlı ve negatif yönlü ilişkilere sahip olduğu ve $\mathrm{R}^{2}$ değerinde artış sağladığı görülmüştür. Elde edilen hiyerarşik regresyon analizi sonuçlarına göre, $\boldsymbol{H}_{\mathbf{2}}$ kabul edilmiş $(\beta=-.389, p<0,001)$ ve YiD'in iP üzerinde düzenleyici etkiye sahip olduğu doğrulanmıştır. Bu düzenleyici etki mevcut ilişkiyi \%57 oranında açıklamaktadır.

Düzenleyici değişken, bağımsız değişkenle bağımlı değişken arasındaki ilişkinin etki gücünü ve yönünü etkileyen bir değişkendir (Baron ve Kenny, 1986: 1174-1175). Rose vd., (2004: 59) bir değişkenin düzenleyici değişken olabilmesi için düzenleyici değişkenin bağımsız değişken ile karşılıklı etkileşiminin bağımlı değişken üzerinde anlamlı bir etkisinin olması gerektiğini belirtmişlerdir. Bu bağlamda Tablo 4'teki üçüncü aşamada hiyerarşik regresyon analizi sonuçlarına göre yenilikçi iş davranışının düzenleyici etkisi incelenmiş ve $\mathrm{H}_{2}$ sınanmıştır. Analiz so- 
nunda yenilikçi iş davranışının, algılanan çalışan performansını ile işletme performansı ilişkisinde düzenleyici etkiye sahip olduğu görülmüştür. Ancak, ilişkinin yönüyle ilgili daha detaylı inceleme yapmak için Cohen vd., (2014) tarafından önerilen süreç izlenmiştir. Bu doğrultuda, düzenleyici değişken olan YiD'in düşük ve yüksek olduğu durumda AÇP ve IP arasındaki ilişkinin anlamlılı̆ını ayrıntılı bir şekilde görebilmek için regresyon eğrisi çizilmiş ve Aiken vd. (1991) tarafından önerilen Slope test analiz yöntemi uygulanmıştır.

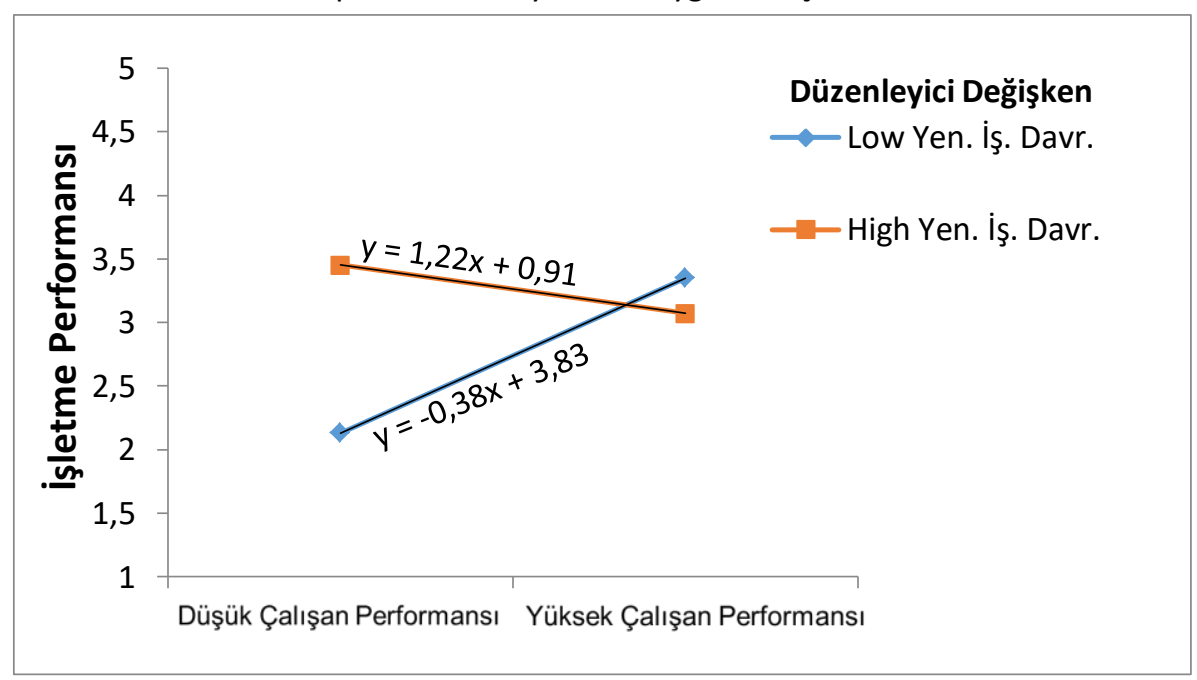

Şekil 3. Düzenleyicilik Etki Slope Analizi

Şekil 3'te de görüldüğü üzere, doğruların paralel olmaması düzenleyici etkinin varlığını kanıtlamaktadır. Algılanan çalışan performansı ile işletme performansı arasındaki ilişki yenilikçi iş davranışının hem düşük olduğu durumda $(\beta=.45, p<.001)$, hem de orta olduğu durumda $(b=.21, p<.05)$ pozitif ve anlamlı iken, yüksek olduğu durumda ise $(b=-.02, p>.005)$ anlamsızdır. Algılanan çalışan performansı ile yenilikçi iş davranışının etkileşimi sonucunda tüm modelin varyansının \%57'sinin açıklandığı saptanmıştır. Bu durumda $\boldsymbol{H}_{\mathbf{2}}$ kabul edilmiştir. Sonuç olarak, yenilikçi iş davranışının bu ilişkide düzenleyici etkiye sahip olduğu tespit edilmiştir.

\section{Tartışma ve Sonuç}

Bu çalışmada algılanan çalışan performansı ile işletme performansı ilişkisinde yenilikçi iş davranışının düzenleyici bir etkisinin olup olmadığı incelenmiştir. Çalışma kapsamında TRB-2 bölgesindeki lojistik firmalarında çalışanlara ulaşılarak, yapılandırılmış bir anket formu aracılığıyla veriler toplanmaya çalışılmıştır. Elde edilen verilere yönelik yapılan korelasyon analizi sonucunda değişkenler arasında yüksek düzeyde pozitif yönlü ilişkiler olduğu tespit edilmiştir. Değişkenler arasındaki ilişkiler literatürdeki çalışmalarla uyumluluk göstermesine karşın düzenleyici etki test edildikten sonraki bulgunun farklılık gösterdiği tespit edilmiştir.

Düzenleyici etkinin varlığını test etmek amacıyla yapılan hiyerarşik regresyon analizinde öncelikle bağımsız değişkenin bağımlı değişken üzerindeki etkisine bakılmıştır. Yapılan analizde algılanan çalışan performansının işletme performansını pozitif yönde etkilediği ve işletme performansını artıran bir etkiye sahip olduğu tespit edilmiştir. Bu bulgunun (Gosselin, 2005; Schuster ve Zingheim, 1996; Wexley, 1994) araştırma bulgusu ile benzerlik göstermektedir. Bir çalışanın bireysel olarak sergilemiş olduğu performansın işletmenin performansını etkileyen ve artıran bir özelliğe sahip olması muhtemeldir. Çünkü çalışanın performansına yönelik olum- 
lu algısının arka planında; yüksek iş tatmini, psikolojik sahiplenme, yeterli örgütsel ve lider desteği, örgütsel özdeşleşme ve bağlılık gibi pek çok pozitif örgütsel davranışın varlığını işaret etmektedir. Dolayısıyla bu durumda işletmenin daha efektif çalışmasını sağlayacak ve çıktılara olumlu yansıyacaktır. Benzer şekilde düzenleyici değişken olan yenilikçi iş davranışının da işletme performansını pozitif etkilediği ve artırdığı tespit edilmiştir. Çalışmanın bu bulgusunun literatürdeki araştırmalar (Akkoç vd., 2011; Hoq, 2009; Ostroff ve Schmitt, 1993; Örnek ve Ayas, 2015; Vincent vd., 2004) ile uyumlu olduğu görülmüştür. Bu durum çalışanların yenilikçi bir iş davranışı sergileme noktasında olumlu oldukları takdirde, başka bir deyişle değişime ve gelişime açık bireyler olması halinde, işletmenin genel performansının olumlu olarak etkileneceği şeklinde yorumlanabilir.

Düzenleyici etkinin varlığına ilişkin yapılan hiyerarşik regresyon analizi sonuçları; algılanan çalışan performansı ile işletme performansı ilişkisinde yenilikçi iş davranışının düzenleyici bir role sahip olduğunu göstermektedir. Bu sonucun kuramsal açıdan desteklendiğini söyleyebiliriz (Gosselin, 2005; Wexley, 1994). Ancak, burada çarpıcı olan şu ki; yenilikçi iş davranışının düzenleyici etkisinin negatif yönlü olmasıdır. Bu durum, yenilikçi iş davranışının bu ilişkiyi azaltan bir etkiye sahip olduğunu göstermektedir.

Bu çalışmanın yenilikçi iş davranışı ve performans literatürünü geliştirmesi beklenmektedir. Konuyla ilgili daha önce yapılan çalışmalar (Arndt ve Sternberg, 2000; Birley ve Westhead, 1990; Gopalakrishnan, 2000; Rosenbusch vd., 2011) bir işletmenin yeniliğe uyum sağlayabilmesinin, yenilikçi bir girdi veya çıktıdan daha fazla işletme performansını etkilediğini ortaya koymaktadır. Başka bir deyişle yeniliğe uyum sağlayamayan işletmeler için yenilikçi iş davranışları aslında yıkım anlamı taşımaktadır. Burada kilit kavram uyumdur. Yapılan bu çalışmada da bu durum kanıtlanmıştır. Algılanan çalışan performansının, işletme performansına dönmesi sürecinde yenilikçi iş davranışı bu beklentiyi olumsuz etkilemektedir. Bu perspektiften çalışmanın performans ile yenilikçi iş davranışı arasındaki ilişkinin anlaşılmasına farklı bir bakış açısı getirdiği düşünülmektedir. Örneklem olarak ele alınan işletmelerdeki çalışanların yenilikçi iş davranışlarına uyum sağlayamadığı, bu nedenle işletme performansının olumsuz etkilendiği düşünülmektedir. Buradan hareketle yeniliğe olan uyumun önemi ortaya çıkmaktadır.

Çalışmanın pratikte de çalışan ve yöneticilere yol gösterici olması beklenmektedir. Araştırmada, bir yeniliğin işletmeye kazandırımasının her zaman, -en azından kısa vadede- bir çıktıya dönüşemeyebileceği kanıtlanmıştır. Bu durumu Schumpeter (1951), girişimciliğin temel fonksiyonlarından olan yeniliğin, yaratıcı yıkımın sonucunda oluştuğunu savunarak açıklamıştır (Akt. Çiçek ve Karakaş, 2017: 134). Burada işletme sahiplerine ve yöneticilere iki tavsiyede bulunulabilir. Öncelikle yenilik sabır gerektiren bir süreçtir. Hissedarların ve yöneticilerin, yenilikçi bir davranışta bulunurken bunu göz ardı etmemeleri gerekmektedir. Yani aslında isminin çağrıştırdığının aksine yenilik meyvesini çok hızlı verebilen bir olgu değildir. Bu nedenle bir yenilik getirileceği zaman, bunun çıktıya dönüşebilmesinin zaman alacağı göz önünde bulundurulmalıdır. İkinci olarak, işletmelerdeki birçok süreçte olduğu gibi yenilikçi davranışlarda da çalışanların göz ardı edilmemesi gerekmektedir. Çalışanlar sürece dahil edilmediği müddetçe, yeniliği kendi güvenliklerine ve yaptıkları işe bir saldırı olarak görüp direnç göstereceklerdir. Bu durum da onların yeniliği kötü bir şeymiş gibi görmelerine ve böylece bireysel performanslarının olumsuz etkilenmesine neden olabilecektir. Doğal olarak bu durum işletme performansına da olumsuz yansıyabilecektir. Süreç, yeniliğin çalışanların da menfaatine olabilecek şekilde dizayn edilmesiyle başlamalıdır. Fakat bu yeniliğe direncin kırılması için yeterli değildir. Bu gerçeğin çalışanlar tarafından kabul görmesi gerekmektedir. Burada iş daha çok 
yöneticilere düşmektedir. Çalışanları sürecin içerisine daha fazla dahil edilip yenilikçi iklimin oluşturulması ancak yöneticilerin çabalarıyla mümkün olabilecektir.

Çalışmada mümkün olduğunca kısıtların minimuma indirilmesine çalışılsa da okuyucunun araştırma bulgularını değerlendirilirken göz önünde bulundurulması gereken bazı kısıtlar mevcuttur. Söz konusu kısıtlardan ilki, araştırmanın örneklem sayısının sınırıılı̆ıdır. Sonraki araştırmalarda örneklem sayısının artırılması, sonuçların genellenebilirliğini artırmak açısından yararlı olabilir. Kısıtlardan ikincisi, örneklemin TRB-2 bölgesindeki lojistik firmaları ile sınırlı olmasıdır. Sonraki araştırmalarda, farklı bölgelerdeki lojistik firmaları ya da farklı sektörlerin araştırmanın örneklemine dâhil edilmesi yararlı olabilir. Üçünü kısıt olarak, örneklemin yalnızca lojistik firmaları çalışanları ile sınırı olması da bir sınırlılık teşkil etmektedir. Gelecek araştırmalar için ise farklı sektör çalışanlarından elde edilen veriler ile yenilikçi iş davranışının çalışan ve işletme performansı ilişkisinde düzenleyici etkisinin araştırılması önerilebilir. 


\section{Eskişehir Osmangazi Üniversitesi iißBF Dergisi}

\section{Kaynaklar}

Aiken, Leona S, West, Stephen G, \& Reno, Raymond R (1991), Multiple Regression: Testing and Interpreting Interactions: Sage.

Akkoç, İrfan, Turunç, Ömer, \& Çalişkan, Abdullah (2011), "Gelişim Kültürü ve Lider Desteğinin Yenilikçi Davranış ve İş Performansına Etkisi: İş-Aile Çatışmasının Aracılık Rolü", ISGUC The Journal of Industrial Relations and Human Resources, Vol. 13, No. 4: 83-114.

Amabile, Teresa M (1988), "A Model of Creativity and Innovation in Organizations", Research in Organizational Behavior, Vol. 10, No. 1: 123-167.

Anitha, Jagannathan(2014), "Determinants of Employee Engagement and Their Impact on Employee Performance", International Journal of Productivity and Performance Management, Vol. 63, No. 3: 308.

Arndt, Olaf, \& Sternberg, Rolf (2000), "Do Manufacturing Firms Profit from Intraregional Innovation Linkages? An Empirical Based Answer", European Planning Studies, Vol. 8, No. 4: 465-485.

Banbury, Catherine M, \& Mitchell, Will (1995), "The Effect of Introducing Important Incremental Innovations on Market Share and Business Survival", Strategic Management Journal, Vol. 16, No. S1: 161-182.

Baron, Reuben M, \& Kenny, David A (1986), "The Moderator-Mediator Variable Distinction in Social Psychological Research: Conceptual, Strategic, and Statistical Considerations", Journal of Personality and Social Psychology, Vol. 51, No. 6: 1173.

Bayrakdaroğlu, A, \& Ege, i (2007), "Performans Ölçümünde Alternatif Bir Yöntem, Yatırımın Nakit Kârlılığı (Cfroi) Ve Halka Açık Turizm Şirketleri Üzerine Bir Uygulama", Anadolu Işletmecilik Kongresi. Kırıkkale, No.: 94-108.

Birley, Sue, \& Westhead, Paul (1990), "Growth and Performance Contrasts between 'Types' of Small Firms", Strategic Management Journal, Vol. 11, No. 7: 535-557.

Brayfield, Arthur H, \& Crockett, Walter H (1955), "Employee Attitudes and Employee Performance", Psychological Bulletin, Vol. 52, No. 5: 396.

Bush, Robert P, Bush, Alan J, Ortinau, David J, \& Hair Jr, Joseph F (1990), "Developing a Behavior-Based Scale to Assess Retail Salesperson Performance", Journal of Retailing, Vol. 66, No. 1: 119-137.

Bushra, Fatima, Ahmad, Usman, \& Naveed, Asvir (2011), "Effect of Transformational Leadership on Employees' Job Satisfaction and Organizational Commitment in Banking Sector of Lahore (Pakistan)", International Journal of Business and Social Science, Vol. 2, No. 18.

Cohen, Patricia, West, Stephen G, \& Aiken, Leona S (2014), Applied Multiple Regression/Correlation Analysis for the Behavioral Sciences, Psychology Press.

Craney, Trevor A., \& Surles, James G. (2002), "Model-Dependent Variance Inflation Factor Cutoff Values", Quality Engineering, Vol. 14, No. 3: 391-403.

Çalışkan, Abdullah (2013), "iç Odaklı Örgüt Kültürünün Yenilikçi Davranışa Etkisinde Personel Güçlendirmenin Aracılık Rolü", Is, Guc: The Journal of Industrial Relations \& Human Resources, Vol. 15, No. 1.

Çiçek, Berat, \& Karakaş, Yusuf Emre (2017), "İ̧̧letme Kuluçkaları Döneminde Inovasyon Hedefi ve Performansı ilişkisi: işGEM Örneği", International Journal of Academic Value Studies (javstudies), Vol. 3, No. 13: 133-145.

De Jong, Jeroen (2006), "Individual Innovation: The Connection between Leadership and Employees' Innovative Work Behavior", No.R200604, EIM Business and Policy Research.

De Jong, Jeroen, \& Den Hartog, Deanne (2010), "Measuring Innovative Work Behaviour", Creativity and Innovation Management, Vol. 19, No. 1: 23-36.

De Jong, Jeroen PJ, \& Den Hartog, Deanne N (2007), "How Leaders Influence Employees' Innovative Behaviour", European Journal of Innovation Management, Vol. 10, No. 1: 41-64.

Dess, Gregory G, \& Robinson Jr, Richard B (1984), "Measuring Organizational Performance in the Absence of Objective Measures: The Case of the Privately-Held Firm and Conglomerate Business Unit", Strategic Management Journal, Vol. 5, No. 3: 265-273.

Drucker, Peter F (1998), "The Discipline of Innovation", Leader to Leader, Vol. 1998, No. 9: 13-15.

Erdem, Barış, Gökdeniz, Ayhan, \& Met, Önder (2011), "Yenilikçilik ve İşletme Performansı ilişkisi: Antalya'da Etkinlik Gösteren 5 Yıldızlı Otel Işletmeleri Örneği", Dokuz Eylül Üniversitesi Iktisadi ve Idari Bilimler Fakültesi Dergisi, Vol. 26, No. 2. 
Erdil, Oya, \& Kitapçı, Hakan (2007), "TKY Araçlarının Kullanımı ve Firma Yenilikçiliğinin Yeni Ürün Geliştirme Hızı ve İşletme Performansına Etkisi", Atatürk Üniversitesi Iktisadi ve Idari Bilimler Dergisi, Vol. 21, No. 1: 233-245.

Erkuş, Ahmet, \& Fındıklı, Mine Afacan (2013), "Psikolojik Sermayenin İş Tatmini, İş Performansı ve İşten Ayrılma Niyeti Üzerindeki Etkisine Yönelik Bir Araştırma", Istanbul University Journal of the School of Business Administration, Vol. 42, No. 2.

Fornell, Claes, \& Larcker, David F (1981), "Evaluating Structural Equation Models with Unobservable Variables and Measurement Error", Journal of Marketing Research, No.: 39-50.

Gates, Stephen (1999), Aligning Strategic Performance Measures and Results, The Conference Board, New York: Conference Board New York.

Gopalakrishnan, Shanthi (2000), "Unraveling the Links between Dimensions of Innovation and Organizational Performance", The Journal of High Technology Management Research, Vol. 11, No. 1: 137-153.

Gosselin, Maurice (2005), "An Empirical Study of Performance Measurement in Manufacturing Firms", International Journal of Productivity and Performance Management, Vol. 54, No. 5/6: 419-437.

Hayes, Andrew F (2012), Process: A Versatile Computational Tool for Observed Variable Mediation, Moderation, and Conditional Process Modeling, Kansas: University of Kansas, KS.

Hoq, Mohammad Ziaul (2009), Innovativeness: Its Antecedents and Impact on SME Business Performance, SSRN: https://ssrn.com/abstract=1851425 veya http://dx.doi.org/10.2139/ssrn.1851425.

Hu, Li-tze, \& Bentler, Peter M (1999), "Cutoff Criteria for Fit Indexes in Covariance Structure Analysis: Conventional Criteria Versus New Alternatives", Structural Equation Modeling: AMultidisciplinary Journal, Vol. 6, No. 1: 1-55.

Işık, Metin (2018), "Bilgi Paylaşımını Etkileyen Faktörler ve Bilgi Paylaşım Sürecinin Yenilikçi İş Davranışına Etkisi", Uluslararası iktisadi ve idari Incelemeler Dergisi, Vol. 17. UiK Özel Sayısı, No.: 641-656.

Janssen, Onne (2005), "The Joint Impact of Perceived Influence and Supervisor Supportiveness on Employee Innovative Behaviour", Journal of Occupational and Organizational Psychology, Vol. 78, No. 4: 573-579.

Kanter, Rosabeth Moss (2009), "When a Thousand Flowers Bloom: Structural, Collective, and Social Conditions for Innovation in Organizations", Knowledge Management and Organisational Design, Vol. 10, No.: 93.

Kheng, Yeoh Khar, Mahmood, Rosli, \& Beris, Sethela June Hamy (2013), "A Conceptual Review of Innovative Work Behavior in Knowledge Intensive Business Services among Knowledge Workers in Malaysia", International Journal of Business, Humanities and Technology, Vol. 3, No. 2: 91-99.

Kılıçer, Tuğba (2011), Kobi'lerin Girişimci Pazarlama Yaklaşımı, Yenilik Yaratma Çabaları, Performansları ve Sahip Yöneticilerin Girişimcilik Tutumları Açısından Profilleri,(Yayımlanmamış Doktora Tezi), Anadolu Üniversitesi, Sosyal Bilimler Enstitüsü: Eskişehir.

Kuratko, Donald F, Hornsby, Jeffrey S, \& Goldsby, Michael G (2011), Innovation Acceleration: Transforming Organizational Thinking: Pearson Higher Ed.

Lado, Mario, \& Alonso, Pamela (2017), "The Five-Factor Model and Job Performance in Low Complexity Jobs: A Quantitative Synthesis", Revista de Psicología del Trabajo y de las Organizaciones, Vol. 33, No. 3: 175-182.

Lebas, Michel J (1995), "Performance Measurement and Performance Management", International Journal of Production Economics, Vol. 41, No. 1-3: 23-35.

Levitt, Theodore (2003), "Yaratıcılık Yetmez", Çev: Ahmet Kardam, Harvard Business Review Dergisinden Seçmeler: Yenilikçilik, No.: 161-184.

Naktiyok, Atılhan, \& Küçük, Orhan (2003), "Küçük Ve Orta Büyüklükteki Işletmelerde (Kobi) Toplam Kalite Yönetimi (Tky) Kritik Faktörlerinin Örgütsel Performans Üzerine Etkileri", Erciyes Üniversitesi iktisadi ve Idari Bilimler Fakültesi Dergisi, No. 21.

Neely, Andy, Gregory, Mike, \& Platts, Ken (1995), "Performance Measurement System Design: A Literature Review and Research Agenda", International Journal of Operations \&Production Management, Vol. 15, No. 4: 80-116.

Noe, Raymond, Hollenbeck, John, Gerhart, Barry, \& Wright, Patrick (2006), Human Resources Management: Gaining a Competitive Advantage, Tenth Global Edition: McGraw-Hill Education.

Osterloh, Margit, \& Frey, Bruno S (2000), "Motivation, Knowledge Transfer, and Organizational Forms", Organization Science, Vol. 11, No. 5: 538-550.

Ostroff, Cheri, \& Schmitt, Neal (1993), "Configurations of Organizational Effectiveness and Efficiency", Academy of Management Journal, Vol. 36, No. 6: 1345-1361. 


\section{Eskişehir Osmangazi Üniversitesi iißBF Dergisi}

Örnek, Ali Şahin, \& Ayas, Siyret (2015), "Entelektüel Sermaye ile Yenilikçi İş Davranışının İşletme Performansına Etkisi: Bilişim Sektörü Uygulaması", Dokuz Eylül Üniversitesi Işletme Fakültesi Dergisi, Vol. 16, No. 2: 91-116.

Pearson, Andrall E (2003), "Yenilikçilikte Kararlı Olma Yolları", Çev: Ahmet Kardam, Harvard Business Review Dergisinden Seçmeler: Yenilikçilik, No.: 37-58.

Rose, Brigid M, Holmbeck, Grayson N, Coakley, Rachael Millstein, \& Franks, Elizabeth A (2004), "Mediator and Moderator Effects in Developmental and Behavioral Pediatric Research", Journal of Developmental \& Behavioral Pediatrics, Vol. 25, No. 1: 58-67.

Rosenbusch, Nina, Brinckmann, Jan, \& Bausch, Andreas (2011), "Is Innovation Always Beneficial? A Meta-Analysis of the Relationship between Innovation and Performance in Smes", Journal of Business Venturing, Vol. 26, No. 4: 441-457.

Salanova, Marisa, Agut, Sonia, \& Peiró, José María (2005), "Linking Organizational Resources and Work Engagement to Employee Performance and Customer Loyalty: The Mediation of Service Climate", Journal of Applied Psychology, Vol. 90, No. 6: 1217.

Schumpeter, Joseph A (1934), "The Theory of Economic Development: An Inquiry into Profits, Capital, Credit, Interest, and the Business Cycle (1912/1934)", Transaction Publishers, Vol. 55, No.

Schumpeter, Joseph A (1951), Essays on Entrepreneurs, Innovations, Business Cycles and the Evolution of Capitalism (Ed. Rv Clemence), New Brunswick and Oxford: Transaction Publishers.

Schuster, Jay R, \& Zingheim, Patricia K (1996), The New Pay: Linking Employee and Organizational Performance: Jossey-Bass.

Scott, Susanne G, \& Bruce, Reginald A (1994), "Determinants of Innovative Behavior: A Path Model of Individual Innovation in the Workplace", Academy of Management Journal, Vol. 37, No. 3: 580-607.

Sureshchandar, GS, Rajendran, Chandrasekharan, \& Anantharaman, RN (2002), "The Relationship between Management's Perception of Total Quality Service and Customer Perceptions of Service Quality", Total Quality Management, Vol. 13, No. 1: 69-88.

Tidd, Joe, Bessant, John, \& Pavitt, Keith (2005), Managing Innovation Integrating Technological, Market and Organizational Change: John Wiley and Sons Ltd.

Toffler, Alvin (2006), Şok: Gelecek Korkusu, İstanbul: Çev: Selami Sargut, Koridor Yayıncılık.

Vincent, Leslie Harris, Bharadwaj, Sundar G, \& Challagalla, Goutam N (2004), "Does Innovation Mediate Firm Performance?: A Meta-Analysis of Determinants and Consequences of Organizational Innovation", No.NSF IGERT0221600.

West, Michael A, \& Farr, James L (1989), "Innovation at Work: Psychological Perspectives", Social Behaviour, Vol. 4, No. 1: 15-30.

Wexley, Kenneth N (1994), Increasing Productivity through Performance Appraisal: Prentice Hall.

Yidong, Tu, \& Xinxin, Lu (2013), "How Ethical Leadership Influence Employees' Innovative Work Behavior: A Perspective of Intrinsic Motivation", Journal of business ethics, Vol. 116, No. 2: 441-455.

Zerenler, Muammer (2005), "Performans Ölçüm Sistemleri Tasarımı ve Üretim Sistemlerinin Performansının Ölçümüne Yönelik Bir Araştırma", Ekonomik ve Sosyal Araştırmalar Dergisi, Vol.1, No. 1: 1-36. 